\title{
Protein Tyrosine Phosphatase 4A2 Expression Predicts Overall and Disease-Free Survival of Human Breast Cancer and Is Associated with Estrogen and Progestin Receptor Status
}

\author{
Sarah A. Andres • James L. Wittliff • Alan Cheng
}

Received: 31 December 2012 / Accepted: 19 March 2013 / Published online: 9 April 2013

(C) Springer Science+Business Media New York 2013

\begin{abstract}
Expression of protein tyrosine phosphatase PTP4A2 (also known as PRL2) has been examined in a variety of human carcinomas, although its role in breast cancer remains inconclusive. Since the majority of previous breast cancer studies utilized tissue biopsies composed of heterogeneous cell populations, we hypothesized that an examination of PTP4A2 expression in carcinoma cells isolated by laser capture microdissection (LCM) would provide a more accurate means of assessing its predictive value. From investigations of 247 human breast cancer biopsies collected under standardized, stringent conditions, total RNA was extracted from LCM-procured carcinoma cells to perform microarray analyses to identify gene signatures associated with breast cancer behavior. Expression of PTP4A2 was corroborated by real-time quantitative polymerase chain reaction (qPCR) and referenced to estrogen and progesterone receptor levels. Patient outcomes for overall and disease-free survival were more favorable ( $p=0.004$ and $p=0.001$, respectively) when the expression of PTP4A2 in breast carcinomas was increased compared to patients with biopsies with decreased PTP4A2 levels. PTP4A2 expression determined either by microarray or $\mathrm{qPCR}$ was
\end{abstract}

Electronic supplementary material The online version of this article (doi:10.1007/s12672-013-0141-2) contains supplementary material, which is available to authorized users.

S. A. Andres $\cdot$ J. L. Wittliff $(\bowtie) \cdot$ A. Cheng Department of Biochemistry and Molecular Biology,

University of Louisville - Health Sciences Center,

HSC Bldg. A-512, 319 Abraham Flexner Way,

Louisville, KY 40292, USA

e-mail: jim.wittliff@louisville.edu

S. A. Andres · J. L. Wittliff · A. Cheng

Institute for Molecular Diversity and Drug Design,

University of Louisville, Louisville, KY 40292, USA elevated in either estrogen receptor (ER)-positive or progestin receptor (PR)-positive breast cancer biopsies compared to ER-negative or PR-negative biopsies. However, PTP4A2 expression was only correlated with overall survival in PRpositive breast carcinomas. These data suggest that PTP4A2 mRNA expression alone may serve as a biomarker for prediction of a breast cancer patient's risk of recurrence and overall survival.

\section{Introduction}

Carcinoma of the breast is a prevalent disease in which genomic approaches are investigated in anticipation of improving diagnosis, treatment, and prevention. As a major health concern, it is the most predominant form of cancer in women in the USA. The American Cancer Society estimates that over 230,000 new cases of breast cancer will be diagnosed in 2012, and almost 40,000 deaths in women will be due specifically to breast cancer, the second highest mortality of all cancer types. It is estimated that $12 \%$ of women born in the USA today will be diagnosed with breast cancer at some point in their lives [1].

Applying genomic and proteomic approaches to investigations of human cancer are often complicated by a lack of standardization in protocols for tissue collection and handling, as well as reliable methods for extracting, purifying, amplifying, and analyzing RNA for gene expression profiling under RNase-free and protease-free conditions. These problems are compounded by the cellular heterogeneity of breast tissue biopsies that are composed of carcinoma cells as well as infiltrating endothelial cells, fibroblasts, macrophages, and lymphocytes, to mention a few [2-4]. Many studies established that stroma surrounding carcinoma cells 
provides the necessary vascular support and extracellular matrix molecules that are required for tumor growth and progression [5-11].

Collection and processing of human tissue biopsies have served primarily for clinical diagnosis and staging of patients with little emphasis on preservation of tissue for genomic and proteomic analyses. Cellular heterogeneity of the tissue section often complicates studies with intact tissues, which may generate misleading findings [2, 4, 12-14]. Therefore, a need was identified to develop a reproducible method to obtain homogeneous cell populations from normal tissue or from cancer biopsies in order to obtain accurate information from molecular analysis. Laser capture microdissection (LCM) provides a rapid and nondisruptive method for procuring homogeneous cell populations for biochemical and molecular biological analyses $[2,3,15]$. Numerous studies employed LCM to isolate specific cell types from heterogeneous specimens for either genomic or proteomic analyses [5-7, 14, 16-19], which allows a focused evaluation of molecular processes involved within the cancer cells themselves.

Increased expression of estrogen receptors $(\mathrm{ER} \alpha)$ in human breast cancers is well documented to be an indicator of increased overall and disease-free survival $[20,21]$ as well as a predictor of response to endocrine therapy [21-24]. There is also an inverse relationship with EGFR expression [24-26], tumor grade, and lymph node involvement, indicating alternative mechanisms for aggressive growth of certain estrogen receptor (ER)-positive tumors. Progestin receptor (PGR) is one of many estrogen-responsive genes expressed in both normal and neoplastic breast epithelia, which is also a clinical biomarker with significant prognostic value in breast cancer management [22, 23, 27, 28]. In general, patients with primary breast carcinomas exhibiting both ER and progestin receptor (PR) have a better prognosis than those with ER-/PR- cancers. Although the relationship between either $\mathrm{ER}+/ \mathrm{PR}-$ or $\mathrm{ER}-/ \mathrm{PR}+$ tumors with prognosis is unclear, some studies suggest that ER/PR expression is related to cross-talk with growth factor receptor signaling [29].

Protein tyrosine phosphatases (PTPs) represent a large family of enzymes that are implicated in multiple cellular processes, including proliferation, growth, and apoptosis [30]. Although many studies have demonstrated increased PTP expression in breast cancer compared to normal tissues [31-34], the causal role linking it to cancer development and progression remains largely open to interpretation.

Protein tyrosine phosphatase 1B (PTP1B) was the first PTP to be identified [35]. It is widely expressed and has been implicated in multiple signaling pathways [36, 37]. Mouse knockout studies have long demonstrated its role in metabolism [38-41]. However, more recent studies have identified an important role in breast cancer as well
[42-44]. PTP1B seems to play a positive role, possibly via activation of the Ras and Src signaling pathways [45-47]. Interestingly, increased PTP1B expression was reported in one third of human breast cancers and indicated poor prognosis of these patients [34].

Another group of PTPs implicated in cancer includes the PTP4A/PRL subfamily that currently comprises PTP4A1 (PRL-1), PTP4A2 (PRL-2), and PTP4A3 (PRL-3). Of these three, PTP4A2 appears to correlate with breast cancer tumor formation and progression [48]. The authors demonstrated that overexpression of PTP4A2 could induce ErbB2induced mouse mammary tumorigenesis. Furthermore, they showed that PTP4A2 expression was increased in breast tumor specimens compared to normal tissue, albeit with a small sample size $(n=7)$. In contrast, another study examined the prognostic significance of PTP4A2 in breast cancer and concluded that PTP4A2 expression did not differ between neoplastic and nonneoplastic human breast cancer tissue specimens [33]. However, LCM was not performed, and PTP4A2 levels were not correlated with other disease parameters. Thus, in order to better evaluate the clinical significance of PTP4A2 in disease outcome of breast cancer patients, we assessed expression of the gene by microarray and by quantitative polymerase chain reaction (qPCR) analyses in biopsies tissues from breast cancer patients. In addition, we also examined relationships with estrogen and progestin receptor status.

\section{Materials and Methods}

Using an IRB-approved database and biorepository composed of de-identified specimens previously collected under stringent conditions [28] for clinical assays of ER and PR, tissue sections of primary invasive ductal carcinomas obtained from 1988 to 1996 were examined using the REMARK criteria [49]. Patients were treated with the standard of care at the time of diagnosis. Tissue-based properties (e.g., pathology, grade, size, and tumor marker expression) and patient-related characteristics (e.g., age, race, smoking status, menopausal status, stage, and nodal status) were utilized to determine relationships between gene expression and clinical parameters.

Carcinoma cells were procured from 247 frozen breast cancer tissue specimens (Table 1) using the PixCell IIe (Arcturus) LCM instrument and workstation using protocols established in our laboratory (cf [4]). A retrospective analysis of gene expression was also performed on intact frozen tissues from 233 biopsies of invasive ductal carcinoma (Table 2). Tissue sections utilized for these analyses contained a median of $60 \%$ breast carcinoma cells (range of 10-95\%) and $25 \%$ stromal cells (range of $5-65 \%)$. 
Table 1 Characteristics of the breast cancer patient population employed in the microarray study

\begin{tabular}{|c|c|}
\hline Patient parameters & $n$ \\
\hline \multicolumn{2}{|l|}{ Median age (range) } \\
\hline 59 years $(21-89.5)$ & 247 \\
\hline \multicolumn{2}{|c|}{ Median observation time (range) } \\
\hline 65 months $(3-155)$ & 247 \\
\hline \multicolumn{2}{|l|}{ Race } \\
\hline White & 211 \\
\hline Black & 34 \\
\hline Other & 2 \\
\hline \multicolumn{2}{|l|}{ Histology } \\
\hline Invasive ductal carcinoma & 193 \\
\hline Lobular carcinoma & 15 \\
\hline Medullary carcinoma & 8 \\
\hline Other/unknown & 31 \\
\hline \multicolumn{2}{|l|}{ Median tumor size (range) } \\
\hline $27 \mathrm{~mm}(3-100)$ & 218 \\
\hline \multicolumn{2}{|l|}{ Stage } \\
\hline 0 & 3 \\
\hline 1 & 60 \\
\hline $2 \mathrm{~A}$ & 85 \\
\hline $2 \mathrm{~B}$ & 55 \\
\hline $3 \mathrm{~A}$ & 22 \\
\hline $3 \mathrm{~B}$ & 13 \\
\hline 4 & 4 \\
\hline Unknown & 5 \\
\hline \multicolumn{2}{|l|}{ Grade } \\
\hline 1 & 14 \\
\hline 2 & 70 \\
\hline 3 & 94 \\
\hline 4 & 1 \\
\hline Unknown & 68 \\
\hline \multicolumn{2}{|l|}{ Estrogen receptor status } \\
\hline Negative & 97 \\
\hline Positive & 150 \\
\hline \multicolumn{2}{|l|}{ Lymph node status } \\
\hline Negative & 125 \\
\hline Positive & 102 \\
\hline Unknown & 20 \\
\hline \multicolumn{2}{|l|}{ Recurrence status } \\
\hline Yes & 98 \\
\hline No & 146 \\
\hline Never disease free & 3 \\
\hline
\end{tabular}

Estrogen Receptor and Progestin Receptor Levels

ER and PR protein levels were determined using either enzyme immunoassay (EIA) or radiolabeled ligand binding assay $[24,28,50]$. Briefly, both methods utilized chilled/frozen specimens that were sliced carefully with a
Table 2 Characteristics of the breast cancer patient population employed in the qPCR study

Patient parameters

Median age (range)

60 years (26-89.5)

Median observation time (range)

63 months (3-153)

Race

White

Black

Histology

Invasive ductal carcinoma

Median tumor size (range)

$28 \mathrm{~mm}$ (4-85)

$3 \mathrm{~B}$

Grade

1

Unknown 46

Estrogen receptor status

Negative $\quad 83$

$\begin{array}{ll}\text { Positive } & 150\end{array}$

Lymph node status

Negative $\quad 122$

Positive 95

Unknown 16

Recurrence status

$\begin{array}{ll}\text { Yes } & 72\end{array}$

No 154

Never disease free $\quad 7$

scalpel on a Petri dish chilled on a frozen ice pack to maintain receptor integrity and then homogenized with a mass-to-buffer ratio of $100 \mathrm{mg}$ wet weight of tissue per

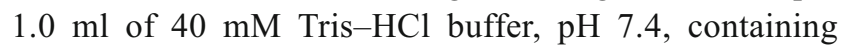
$1.5 \mathrm{mM}$ EDTA, $10 \%$ glycerol, $10 \mathrm{mM}$ sodium molybdate, $10 \mathrm{mM}$ monothioglycerol, and $1 \mathrm{mM}$ PMSF [28]. Extracts were prepared by centrifugation at $100,000 \times \mathrm{g}$ for $30 \mathrm{~min}$.

A complete ligand binding assay was comprised of duplicates of six increasing concentrations of radiolabeled $\left[{ }^{3} \mathrm{H}-\right.$ estradiol-17 $\beta$ ] with and without unlabeled diethylstilbestrol in a titration format $[28,50]$. Reactions were incubated overnight $(12-18 \mathrm{~h})$ at $4{ }^{\circ} \mathrm{C}$. Unbound ligand was removed 
by addition of dextran-coated charcoal, incubated for $15 \mathrm{~min}$, and then centrifuged at $3,300 \times \mathrm{g}$ for $15 \mathrm{~min}$ at $4{ }^{\circ} \mathrm{C}$. Supernatant was removed and radioactivity was detected in a liquid scintillation counter. Specific ligand binding capacity, reflecting the receptor level, was expressed as femtomole per milligram cytosol protein while the resulting apparent dissociation constant (Kd value) determined by Scatchard analysis was expressed as $M$.

Determination of ER and PR levels by EIA employed a kit formerly distributed by Abbott Laboratories [28, 50]. This protocol utilized beads coated with anti-ER monoclonal antibodies which were incubated with the tissue extracts $[28,50]$. Unbound materials were aspirated and washed, before the bead-associated receptor protein was incubated with antireceptor antibodies conjugated with horseradish peroxidase. Color was developed and measured with a spectrometer at a wavelength of $492 \mathrm{~nm}$. The receptor level (mass) was expressed as femtomole per milligram cytosol protein.

\section{RNA Isolation and qPCR Analysis}

Total RNA from LCM-procured cells was isolated using PicoPure $^{\circledR}$ (Arcturus/Life Technologies) kits, which are optimized for extracting RNA from cells procured by LCM. RNA in intact tissue sections, extracted with RNeasy ${ }^{\circledR}$ (Qiagen, Valencia, CA) kits, was analyzed prior to proceeding with LCM by utilization of the Bioanalyzer ${ }^{\mathrm{TM}}$ instrument and reagents (Agilent Technologies, Palo Alto, CA), which estimates the integrity of total RNA through analysis of the $18 \mathrm{~S}$ and $28 \mathrm{~S}$ rRNA profiles given by electrophoretic separation, and a RNA integrity number which provides a numerical estimate of RNA integrity of the sample. Total RNA from either intact tissue sections or LCM-procured cells was reverse transcribed, and cDNA obtained was diluted tenfold in $2 \mathrm{ng} / \mu$ l polyinositol (Sigma) and used for the $\mathrm{qPCR}$ reactions. qPCR reactions were performed using a total volume of $10 \mu \mathrm{l}$, containing Power $\mathrm{Sybr}^{\circledR}$ Green PCR Master Mix (Applied Biosystems), forward/reverse primers, and cDNA obtained from the reverse transcription reaction. Primers were designed using Primer Express ${ }^{\circledR} 3.0$ (Applied Biosystems). Relative gene expression analyses were performed using the $\Delta \Delta \mathrm{Ct}$ method using $\beta$-actin (ACTB) as a reference gene. Expression of genes was compared to those present in Universal Human Reference RNA (Stratagene, La Jolla, CA) in order to obtain a relative expression level of target gene produced.

\section{Statistical Analyses}

$T$ tests and analysis of variance were performed either in Microsoft ${ }^{\circledR}$ Excel or GraphPad Prism ${ }^{\circledR}$ version 5 (GraphPad Software, La Jolla, CA). Box and whisker plots and Kaplan-Meier survival curves were generated in GraphPad
Prism ${ }^{\circledR}$ version 5. Univariate and multivariate Cox regressions were performed with SPSS ${ }^{\circledR}$ Statistics 20 (SPSS Inc., Chicago, IL) for correlations with disease-free (DFS) and overall survival (OS). Survival calculations were performed using $\log _{2}$ transformations of relative gene expression data.

\section{MCF-7 Cell Culture Experiments}

The MCF-7 breast cancer cell line was obtained from the American Type Culture Collection (Virginia) and maintained in DMEM supplemented with $10 \%$ FBS. Cells were serum starved for $24 \mathrm{~h}$, followed by treatment with $10 \mathrm{nM}$ estradiol- $17 \beta$ for 6 or $24 \mathrm{~h}$. Cells were washed once with PBS, followed by RNA extraction and cDNA synthesis as described above.

\section{Results}

Clinical Outcomes Using Microarray Results of LCM-Procured Breast Carcinoma Cells

Analyses of LCM-procured cells from primary breast cancer lesions have yielded encouraging results regarding the relationship between PTP4A2 expression and risk of breast cancer recurrence. Kaplan-Meier analyses and Cox regressions were utilized to identify associations of PTP4A2 expression with metastatic spread and patient survival. Figure 1 illustrates Kaplan-Meier plots using the microarray data of LCM-procured carcinoma cells from primary breast cancer biopsies of 247 patients. The plot for OS (Fig. 1b) showed separation of the survival curves $(p=0.05,95 \%$ confidence interval (CI) of hazards ratio (HR), 0.99-2.47) when the patient population was stratified by the median PTP4A2 gene expression levels in breast carcinoma biopsies. However, DFS for the patient population (indicating time until disease recurrence) was not statistically significant $(p=0.27)$ when the same PTP4A2 cutoff value was employed in the Kaplan-Meier analysis (Fig. 1a). The latter result was confirmed by Cox regression $(p=0.10, \mathrm{HR}=$ 0.78). These results suggest that elevated PTP4A2 gene expression appears to correlate positively with increased overall survival of breast cancer patients.

Since a patient's treatment regimen can affect the survival outcomes observed, additional survival curves were composed of patients that did not receive a particular therapy (i.e., hormone therapy, chemotherapy, or radiation therapy). When patients who had not received hormone therapy were stratified by PTP4A2 gene expression levels in LCMprocured carcinoma cells (Fig. 2a, b), the curves for DFS and OS were separated (DFS $p=0.02,95 \%$ CI of HR 0.33 0.91 ; OS $p=0.01$; $95 \%$ CI of HR $0.28-0.86$ ). Similarly, when patients who had not received chemotherapy were 


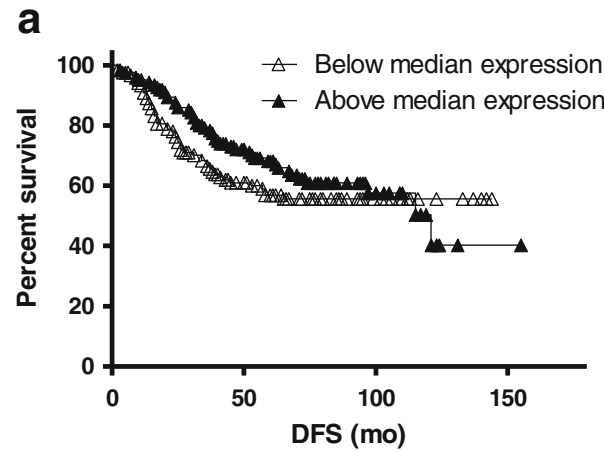

Fig. 1 Kaplan-Meier plots using microarray data of LCM-procured carcinoma cells from 247 primary breast cancer biopsies. a When the patient population was stratified by the median PTP4A2 gene expression level, the plot for DFS was not

stratified by PTP4A2 expression levels, the Kaplan-Meier curves for DFS and OS (Fig. 2c, d) were separated. However, differences in survival were observed only for OS (DFS $p=0.11$; OS $p=0.03$; $95 \%$ CI of HR, 0.26- b

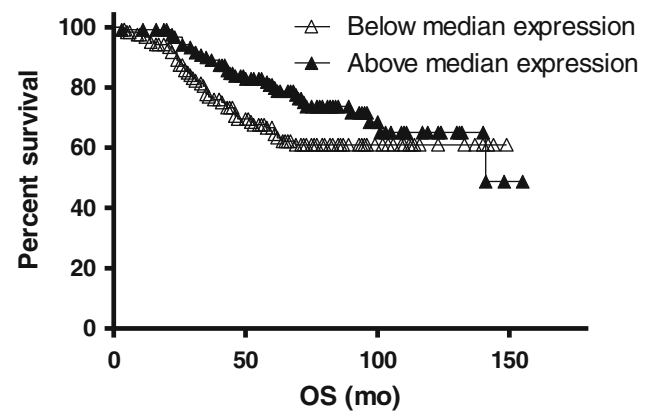

statistically significant $(p=0.27)$. b The plot for OS showed separation of the survival curves $(p=0.05,95 \%$ CI of HR 0.99 2.47) when the patient population was stratified by the median PTP4A2 gene expression level

0.93). Finally, when patients who had not received radiation therapy were stratified by PTP4A2 expression levels (Fig. 2e, f), differences in patient survival were observed (DFS $p=0.04,95 \%$ CI of HR 0.36-0.98; OS $p=0.05,95 \%$
Fig. 2 Kaplan-Meier plots using microarray data of LCMprocured carcinoma cells from patient cohorts not receiving various therapies. a Patients not receiving hormone therapy were stratified by PTP4A2 gene expression levels for DFS $(n=168, p=0.02,95 \%$ CI of HR 0.33-0.91). b Patients not receiving hormone therapy were also analyzed for OS $(p=0.01,95 \%$ CI of HR 0.28 $0.86)$. c Patients not receiving chemotherapy were stratified by PTP4A2 expression levels for DFS $(n=156, p=0.11)$. d Patients not receiving chemotherapy also analyzed for OS $(p=0.03,95 \%$ CI of HR $0.26-0.93)$. e Patients not receiving radiation therapy were stratified by PTP4A2 expression levels for DFS $(n=192, p=0.04,95 \%$ CI of HR 0.36-0.98). f Patients not receiving radiation therapy were also analyzed for OS ( $p=0.05,95 \% \mathrm{CI}$ of HR 0.32-0.99)
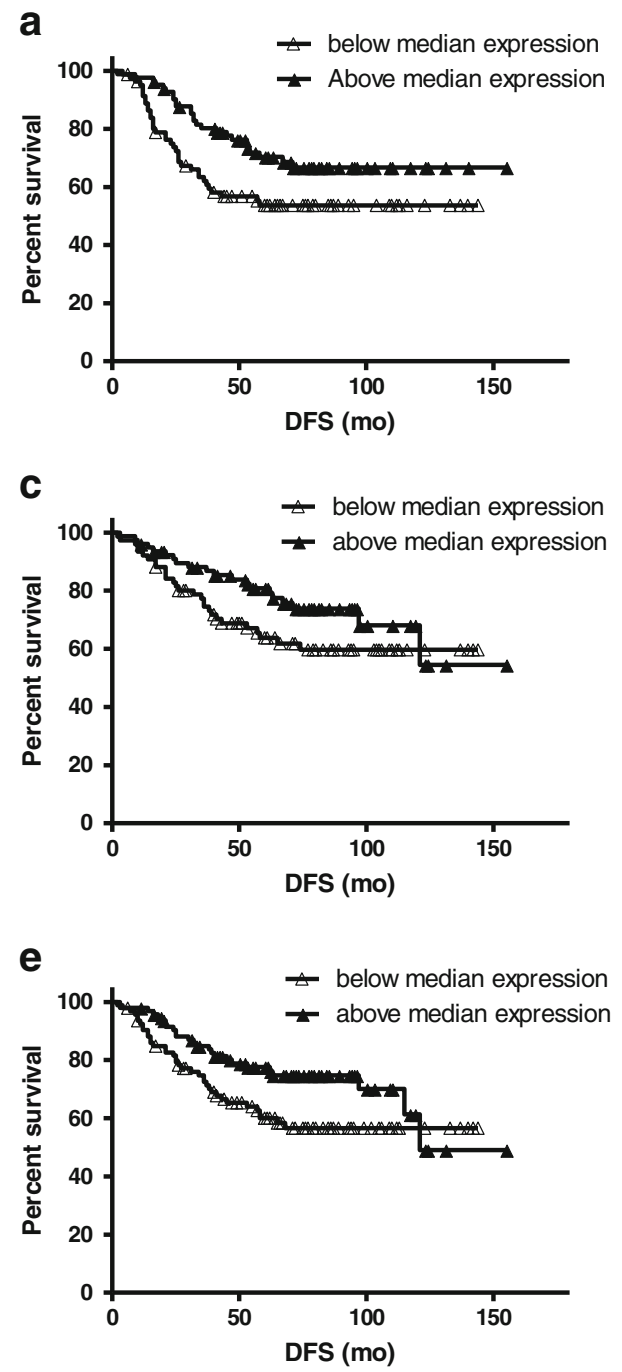
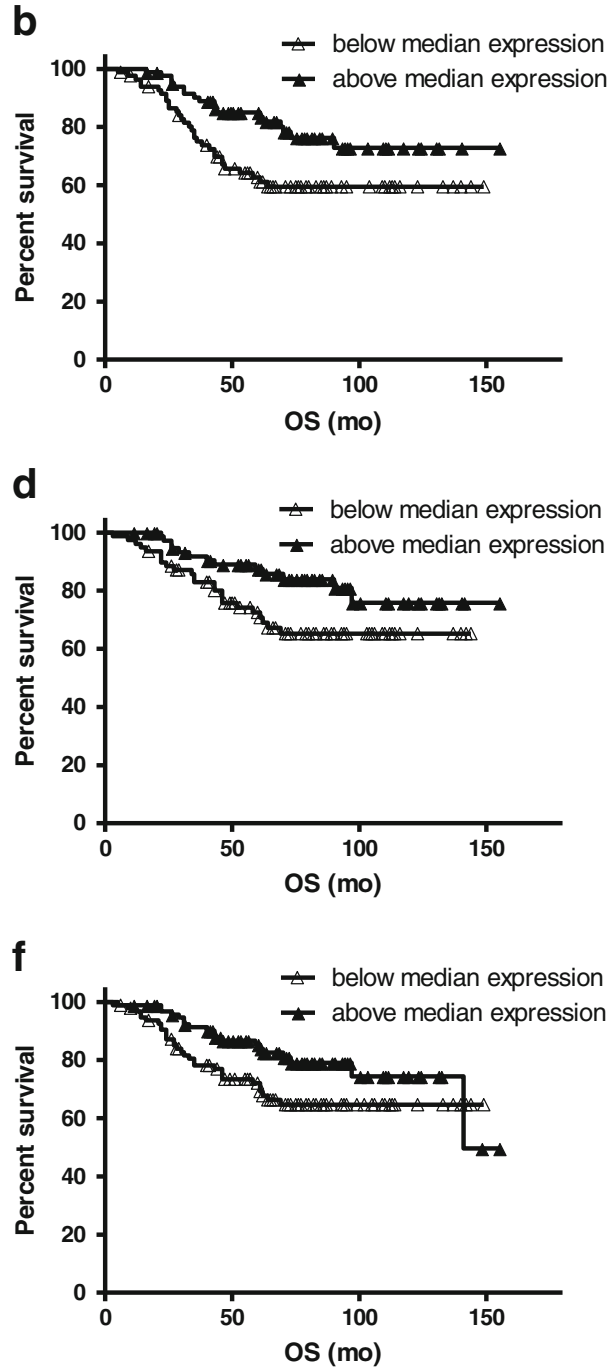
CI of HR 0.32-0.99). These results clearly indicate that the observed differences in survival were not due solely to patient treatment modalities.

Association of PTP4A2 Expression by Microarray, ER or PR Status, and Clinical Parameters

The levels and distribution of PTP4A2 in LCM-procured carcinoma cells are illustrated in Fig. 3a. To assess the relationship of PTP4A2 expression and either ER or PR protein levels, results from microarray analyses of PTP4A2 present in the LCM-procured carcinoma cells were examined as a function of the levels of the two conventional biomarkers (Fig. 3b), without regard to clinical outcome. PTP4A2 expression was significantly elevated in patients with ER+ tumors compared to those with ER- tumors $(p<0.001$, Fig. 3b). Similarly, PTP4A2 gene expression levels were elevated considerably in patients with $\mathrm{PR}+$ tumors compared to those with PR - cancers $(p<0.001$, Fig. $3 b)$. Additional supporting results were observed when comparing gene expression levels of PTP4A2 with ESR1 and PGR expression (ESR1 Pearson correlation of $0.44, p<0.001$; PGR Pearson correlation of $0.44, p<0.001)$. Although differences in PTP4A2 gene expression were noted in patients with carcinomas exhibiting differing hormone receptor protein levels, no differences in patient survival were noted when the population was stratified either by ER or PR status of the tumor prior to assessment of PTP4A2 levels (Figs. 4 and 5).
To further investigate the relationship of ER and PR status within a patient's tumor with PTP4A2 gene expression, additional Cox regression survival analyses were performed. Of the 150 patients with $\mathrm{ER}+$ tumors, 122 were $\mathrm{ER}+/ \mathrm{PR}+$ and 28 were $\mathrm{ER}+/ \mathrm{PR}-$. Patients that had ER+ tumors (regardless of PR status) did not show a correlation of PTP4A2 levels with survival (DFS $p=0.43$; OS $p=0.68$ ). Also, PTP4A2 levels in patients with $\mathrm{ER}+/ \mathrm{PR}+$ or $\mathrm{ER}+/ \mathrm{PR}$ - tumors were not correlated with survival $(\mathrm{ER}+/ \mathrm{PR}+\mathrm{DFS}, p=0.65$, OS, $p=0.83$; $\mathrm{ER}+/ \mathrm{PR}-\mathrm{DFS}, p=0.83$, OS, $p=0.92$ ).

To evaluate the association of PTP4A2 levels with various clinical parameters, PTP4A2 gene expression levels were compared to nodal status, tumor grade, size, stage, and treatment regimen. There was no significant difference in PTP4A2 levels in patients with differing therapies (Supplementary Fig. 11a, c, and e). Levels of PTP4A2 decreased with increasing tumor grade ( $p=0.02$, Fig. 3 c), while correlation to the other clinical parameters was not statistically significant (Supplementary Fig. 12a-d).

Association of PTP4A2 Expression by qPCR, ER or PR Status, and Clinical Outcome

The latter results led us to examine the relationship between the expression of PTP4A2 in breast cancers using different analytical platforms. Gene expression analyses of PTP4A2 were performed by qPCR in 119 intact tissue sections of invasive ductal carcinomas in order to validate the
Fig. 3 Levels of PTP4A2 gene expression in LCM-procured breast cancer cells. a Levels and distribution of PTP4A2 levels in 247 patient samples (horizontal line indicates the median). b Levels of PTP4A2 were elevated in patients with $\mathrm{ER}+$ tumors compared to those with ER- tumors $(p<0.001)$, and similarly, PTP4A2 gene expression levels were elevated in patients with $\mathrm{PR}+$ tumors compared to those with PRbiopsies $(p<0.001)$. $\mathbf{c}$ Levels of PTP4A2 decreased with increasing tumor grade $(p=0.02)$ a
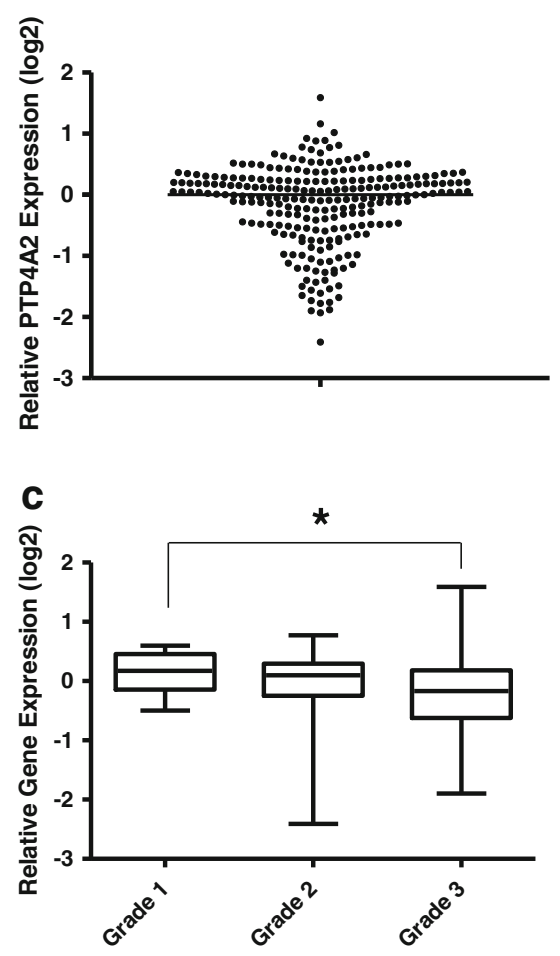

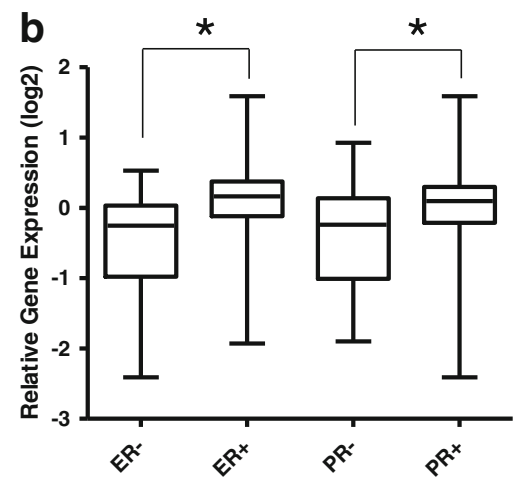


Fig. 4 Relationship of PTP4A2 gene expression with survival of patients with differing ER status of breast cancer. a When patients with $\mathrm{ER}+$ cancers $(n=150)$ were stratified by the median PTP4A2 gene expression level, no significant difference was observed in DFS $(p=0.45)$. b No significant difference was observed in OS of patients with ER+ cancers $(p=0.33)$. c When patients with ER- cancers $(n=97)$ were stratified by the median gene expression level, no significant difference was observed in DFS $(p=0.44)$. d No significant difference was observed in OS of patients with ER- breast cancers $(p=0.47)$
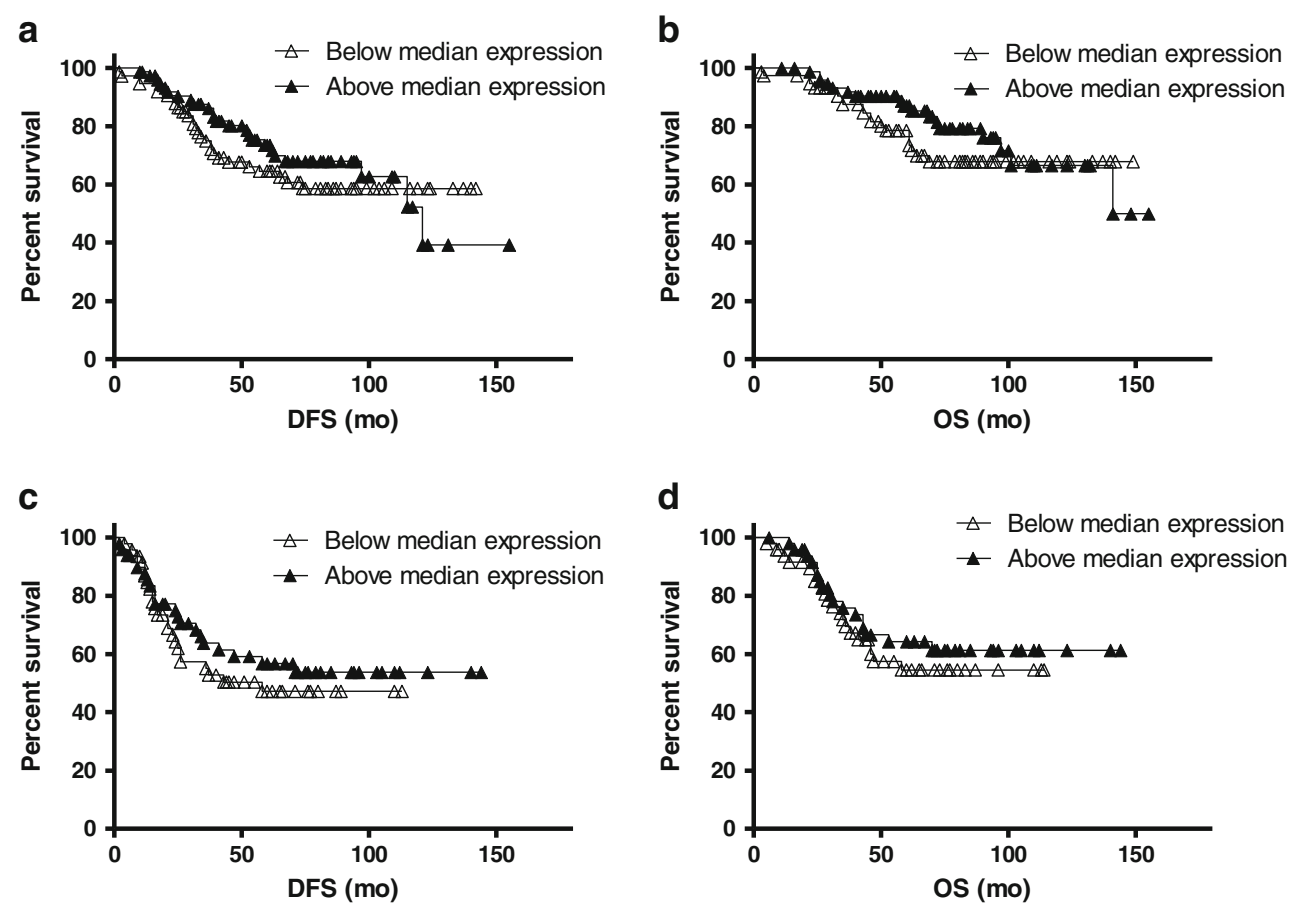

d

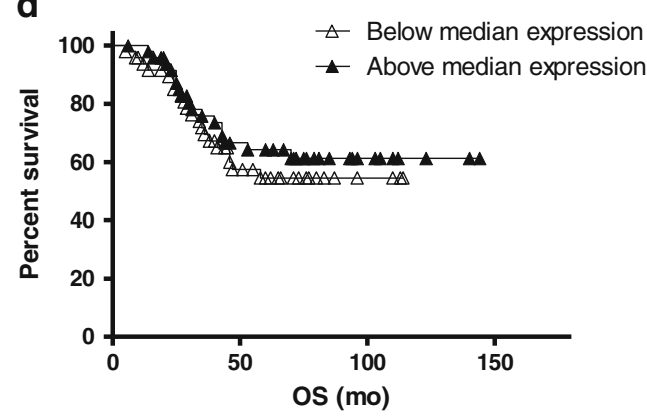

microarray data of LCM-procured carcinoma cells. A Pearson analysis yielded a correlation of $0.42(p<0.001)$, indicating a positive relationship of the gene expression results obtained by qPCR and by microarray. Therefore, additional qPCR analyses of PTP4A2 gene expression were performed using intact tissue sections of 233 primary invasive ductal carcinomas. When the patient population was stratified by the median PTP4A2 gene expression level in the breast cancer (Fig. 6), the Kaplan-Meier plot for DFS was statistically significant $(p=0.01,95 \%$ CI of HR 0.34
0.88). The plot for OS also exhibited statistically significant separation of the survival curves $(p=0.002,95 \%$ CI of HR $0.29-0.76$ ), when the patient population was stratified by the median PTP4A2 gene expression level in the breast carcinoma. In contrast, when results were analyzed as a continuous variable using Cox regressions to identify associations of PTP4A2 mRNA levels with breast carcinoma recurrence and patient survival, PTP4A2 expression measured by qPCR was correlated with DFS $(p=0.004, \mathrm{HR}=$ $0.79)$ and $\mathrm{OS}(p=0.001, \mathrm{HR}=0.77)$. Collectively, these
Fig. 5 Relationship of PTP4A2 gene expression with survival of patients with differing PR status of breast cancer. a When patients with $\mathrm{PR}+$ cancers $(n=157)$ were stratified by the median PTP4A2 gene expression level, no significant difference was observed in DFS $(p=0.18)$. b No significant difference was observed in OS of patients with $\mathrm{PR}+$ cancers $(p=0.20)$. c When patients with PR- cancers $(n=90)$ were stratified by the median gene expression level, no significant difference was observed in DFS $(p=0.15)$. d No significant difference was observed in OS of patients with $\mathrm{PR}-$ breast cancers $(p=0.08)$
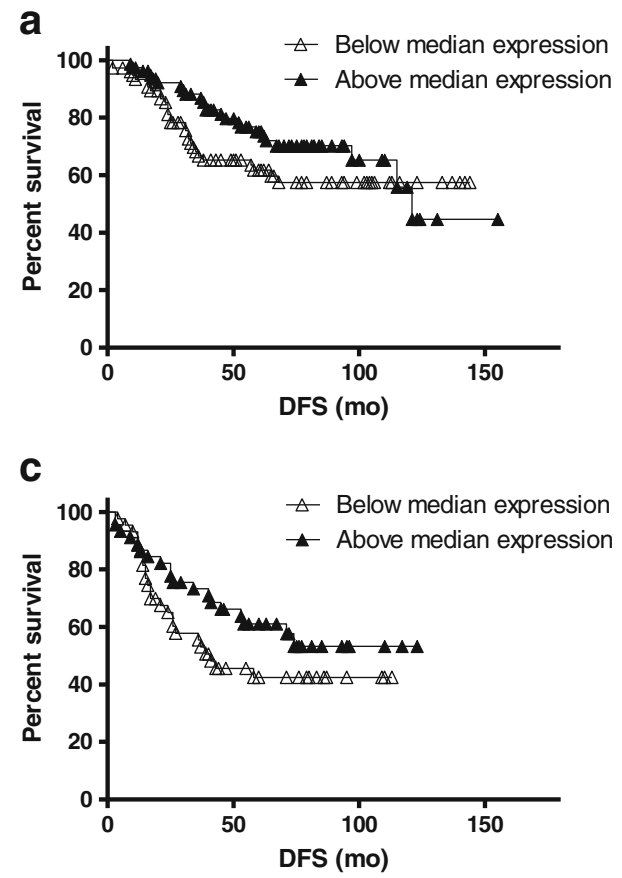

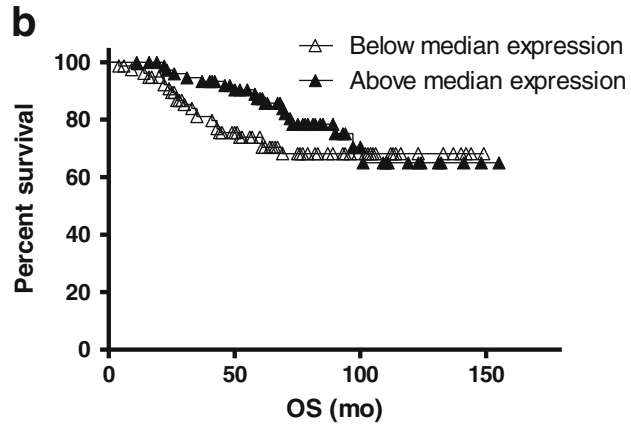

d

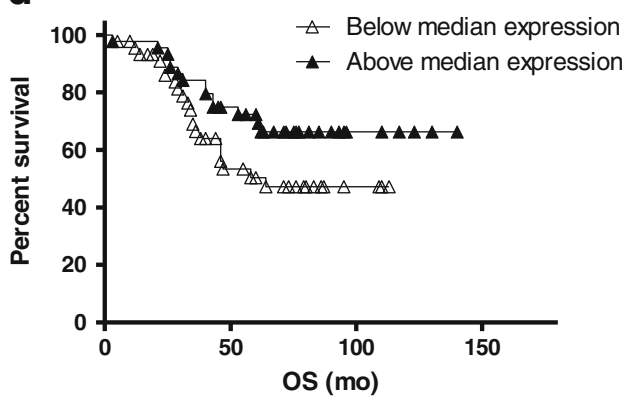




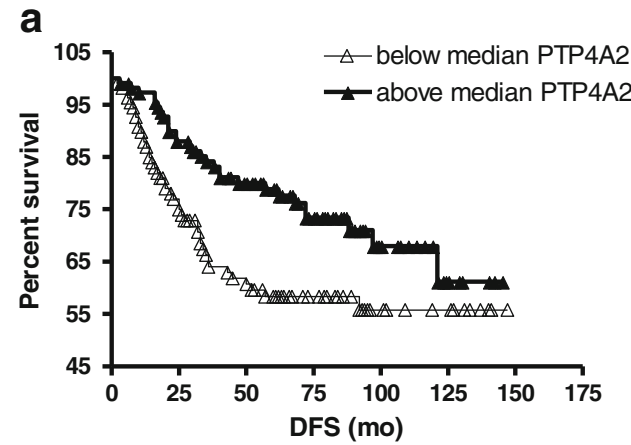

Fig. 6 Kaplan-Meier plots using qPCR data of intact tissue sections from 233 primary invasive ductal carcinomas. a When the patient population was stratified by the median PTP4A2 gene expression level, the plot for DFS illustrated a statistically significant difference in

results suggest that elevated PTP4A2 gene expression correlates positively with increased overall survival, as well as disease-free survival.

Since a patient's treatment regimen may affect the survival outcomes observed, additional survival curves were prepared with patients that did not receive a particular therapy (i.e., hormone therapy, chemotherapy, or radiation therapy). When patients not receiving hormone therapy were stratified by PTP4A2 gene expression levels in breast carcinoma tissue biopsies (Fig. 7a, b), the differences in patient survival were similar to those observed in the entire population (DFS $p=0.002,95 \%$ CI of HR 0.69 0.72 ; OS $p=0.03,95 \%$ CI of HR $0.29-0.94)$. When patients not receiving chemotherapy were stratified by PTP4A2 expression levels (Fig. 7c, d), no statistically significant differences on DFS or OS were observed. When patients who had not received radiation therapy were stratified by PTP4A2 expression levels, no statistically significant difference in DFS was observed (Fig. 7e). However, the same patients exhibited a statistically significant difference for OS (Fig. 7f, $p=0.008$, $95 \%$ CI of HR $0.28-0.83$ ) when stratified by PTP4A2 expression levels. These results clearly suggest that the differences in patient survival observed were not due solely to patient treatment modality.

The levels and distribution of PTP4A2 in LCM-procured carcinoma cells are illustrated in Fig. 8a. Since both ER and PR in a breast carcinoma serve as biomarkers of a patient's prognosis and likelihood of responding to hormonal therapy such as tamoxifen [24, 28], the relationship between PTP4A2 expression validated by qPCR in intact tissue sections was determined in regard to either ER or PR status of the cancer biopsy. Similarly, to that observed in the patient population whose breast carcinoma cells (procured by LCM) were analyzed by microarray, ER+ breast cancers exhibited significantly elevated levels of PTP4A2 mRNA compared to ER- breast cancers $(p<0.001$, Fig. 8 b). This

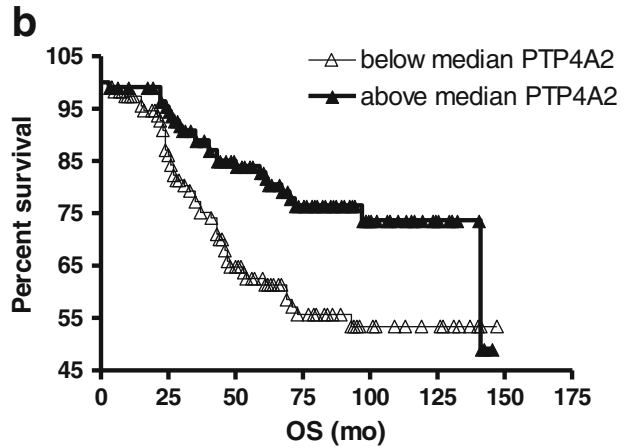

survival curves $(p=0.01,95 \%$ CI of HR $0.34-0.88)$. b The plot for OS also showed significant separation of the survival curves $(p=0.002$, $95 \%$ CI of HR $0.29-0.76$ ) when the patient population was stratified by the median PTP4A2 gene expression level in the tissue biopsy

interesting association was also observed for $\mathrm{PR}+$ tumors $(p<0.001$, Fig. $8 b)$ in that PTP4A2 mRNA levels were increased compared to that of $\mathrm{PR}-$ breast biopsies. These results using protein levels of ER and PR were corroborated when associations of the gene expression levels of the three analytes, PTP4A2 with ESR1 or PGR, were examined. A correlation of PTP4A2 mRNA levels between either receptor gene was observed (ESR1 Pearson correlation of 0.66, $p<0.001$; PGR Pearson correlation of $0.50, p<0.001$ ).

To evaluate the association of PTP4A2 levels with various clinical parameters, PTP4A2 gene expression levels were compared to nodal status, tumor grade, size, stage, and treatment regimen. Levels of PTP4A2 measured by qPCR were significantly correlated to nodal status $(p=0.004$, Fig. $8 \mathrm{c}$ ) and tumor grade ( $p=0.04$, Fig. $8 d$ ), while relationships with the other clinical parameters were not statistically significant (Supplementary Fig. 12e-h). There was a significant difference in PTP4A2 levels in patients receiving chemotherapy and radiation therapy (Supplementary Fig. 11d, f). This is more likely an indirect effect due to associations of PTP4A2 levels with other clinical parameters indicating poor prognosis (nodal status and grade, as described in Supplementary Fig. 12), since all treatments were administered to the patients after tissue collection.

\section{Clinical Utility of PTP4A2 Expression in Breast Carcinomas Exhibiting Different Steroid Receptor Status}

Building upon the findings described above for qPCR measurements of PTP4A2, the clinical utility of determining mRNA levels of the putative biomarker was assessed in patients with breast carcinomas exhibiting different ER or PR levels. The ER and PR protein cutoff values used to assign receptor status that were employed in the KaplanMeier analyses were those approved by the FDA [28, 50]. As shown in Fig. 9, although there appeared to be a survival advantage in DFS and OS of breast cancer patients with 
Fig. 7 Kaplan-Meier plots using qPCR data of tissue from patient cohorts not receiving various therapies. a Patients not receiving hormone therapy were stratified by PTP4A2 gene expression levels for DFS $(n=158, p=0.002,95 \%$ CI of HR 0.69-0.72). b Patients not receiving hormone therapy were also analyzed for OS $(p=0.03,95 \%$ CI of HR 0.29 $0.94)$. c Patients not receiving chemotherapy were stratified by PTP4A2 expression levels for DFS $(n=151, p=0.81)$. d Patients not receiving chemotherapy also analyzed for OS $(p=0.17)$. e Patients not receiving radiation therapy were stratified by PTP4A2 expression levels for DFS $(n=191, p=0.08)$. f Patients not receiving radiation therapy were also analyzed for OS ( $p=0.008,95 \% \mathrm{CI}$ of HR 0.28-0.83) a

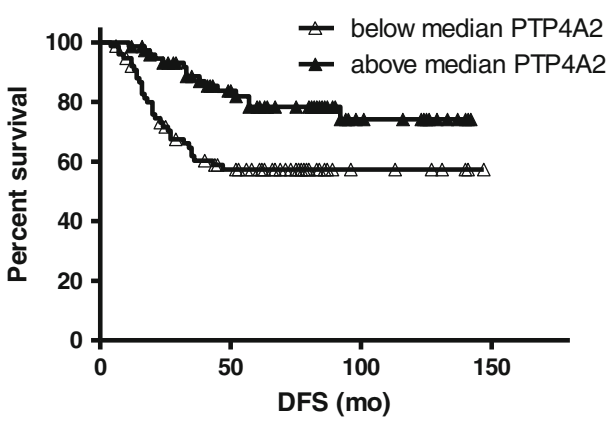

C
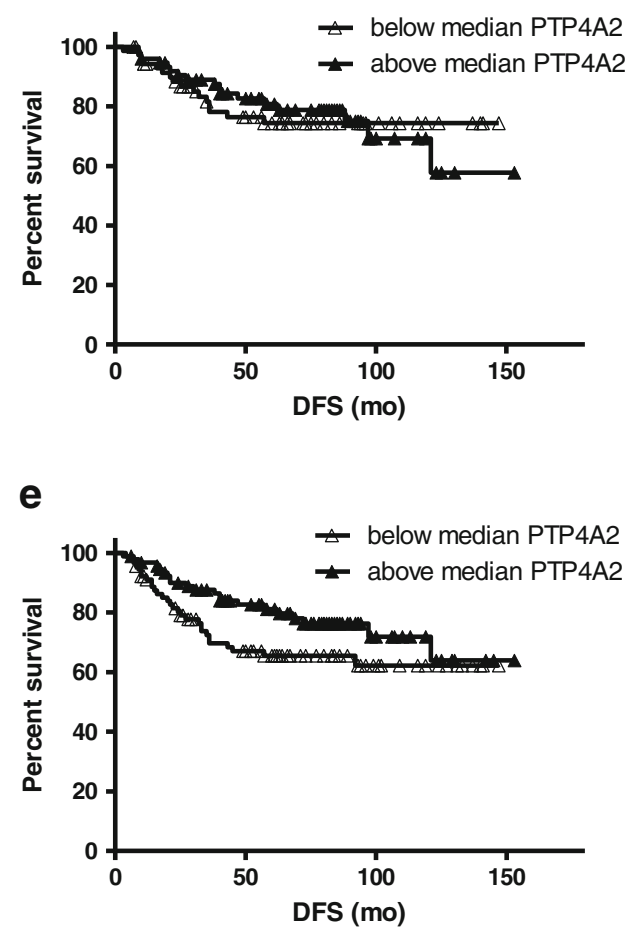

b

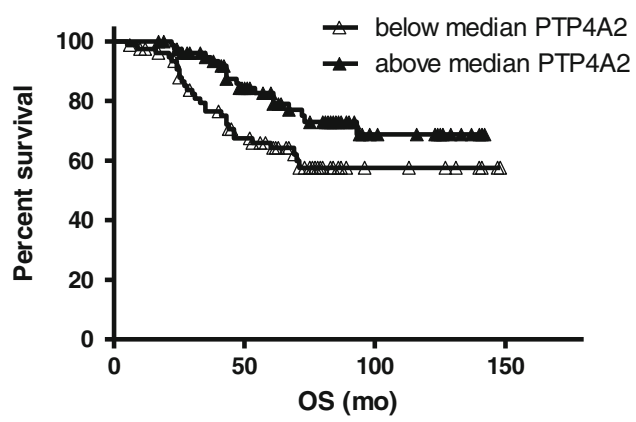

d

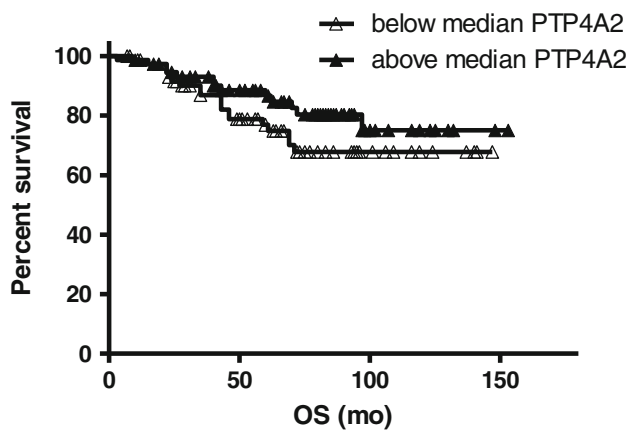

f

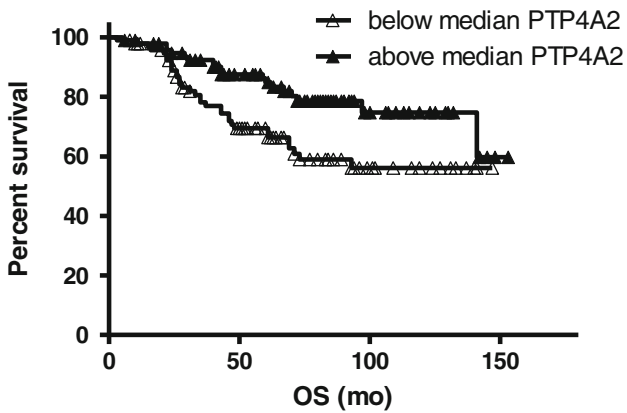

PTP4A2 levels expressed above the median compared to those with below median expression, the results were not statistically significant when comparing ER statuses. Similar results were observed when clinical outcomes were compared in patients with PTP4A2 mRNA levels in relation to PR protein status (Fig. 10), with one exception (Fig. 10b). Breast cancer patients exhibiting an elevated expression of PTP4A2 mRNA levels in biopsies containing PR exhibited highly significant overall survival $(p=0.014,95 \%$ CI of HR $0.25-0.85$, Fig. 10b). These preliminary results suggest that measurements of PTP4A2 expression levels in PR+ breast cancers aid greatly in identifying patient subtypes exhibiting different risks of recurrence.

In the 233 patients with intact breast cancer tissues analyzed by qPCR, PTP4A2 was significantly associated with DFS and OS ( $p=0.004$ and $p=0.001$, respectively). Within the 150 patients with ER+ tumors, 133 were $\mathrm{ER}+/ \mathrm{PR}+$ and 17 were $\mathrm{ER}+/ \mathrm{PR}-$. Cox regression analyses were performed in each of the three groups with the following results: (1) $\mathrm{ER}+$ (regardless of PR status): DFS $p=0.027$, OS $p=0.023$; (2) $\mathrm{ER}+/ \mathrm{PR}+$ : DFS $p=0.16$, OS $p=0.06$; (3) and $\mathrm{ER}+/ \mathrm{PR}-$ : DFS $p=0.08$, OS $p=0.45$. There does not appear to be a difference between the tumor marker profiles typically associated with the luminal A and B subtypes of breast cancer in either of the patient populations investigated (LCM-procured cells were analyzed by microarray or intact tissue analyzed by qPCR). However, this may be due to the small population size of the ER+/PR - subgroup (microarray $n=28$ and qPCR $n=17)$ compared to the $\mathrm{ER}+/ \mathrm{PR}+$ population (microarray $n=150$ and qPCR $n=150$ ).

In an effort to understand any potential relationship of PTP4A2 expression with the presence of estrogen receptors, we utilized the online software tool Dragon ERE Finder, version 3.0 [51]. When the promoter region of PTP4A2 was used as the input sequence, no ERE sequences were predicted. When the entire gene sequence was uploaded, two ERE 
Fig. 8 Levels of PTP4A2 gene expression in breast cancers. a Levels and distribution of PTP4A2 in breast cancer tissues measured by qPCR. b Levels of PTP4A2 were elevated in patients with ER+ cancers compared to those with similarly, PTP4A2 gene expression levels were elevated in patients with $\mathrm{PR}+$ cancers compared to those with c Levels of PTP4A2 were decreased in node-positive patients $(p=0.004)$. d Levels of PTP4A2 decreased with increasing tumor grade $(p=0.04)$ ER- cancers $(p<0.001)$, and PR - tissue biopsies $(p<0.001)$.
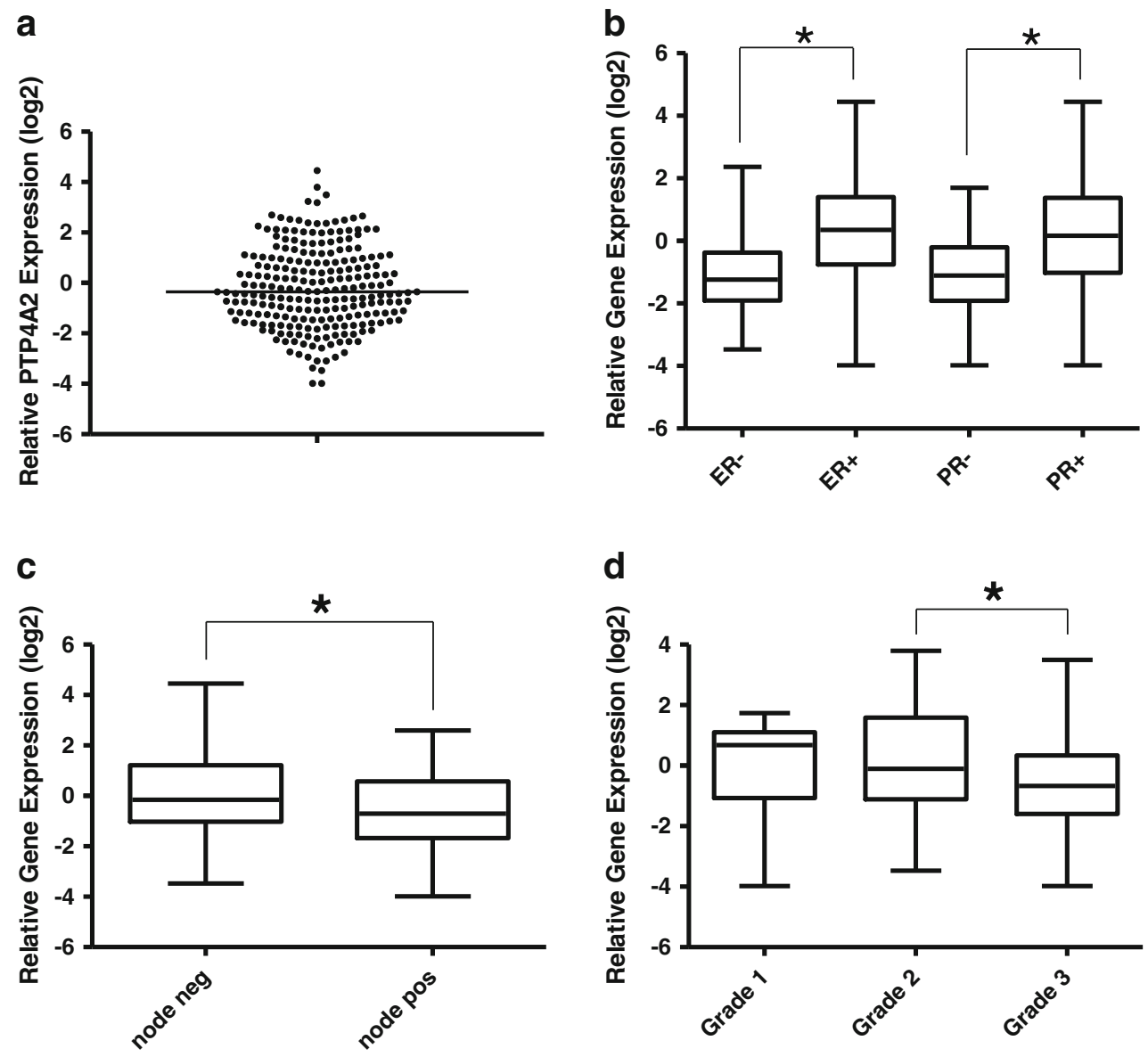

Fig. 9 Relationship of PTP4A2 gene expression with survival in patients with differing ER status of breast cancer. a When patients with ER+ cancers $(n=146)$ were stratified by the median PTP4A2 gene expression level, no significant difference was observed in DFS $(p=0.25)$. b No significant difference was observed in OS of patients with ER+ cancers $(p=0.15)$. $\mathbf{c}$ When patients with ER- cancers $(n=84)$ were stratified by the median gene expression level, no significant difference was observed in DFS $(p=0.14)$. d No significant difference was observed in OS of patients with ER- breast cancers $(p=0.41)$ a

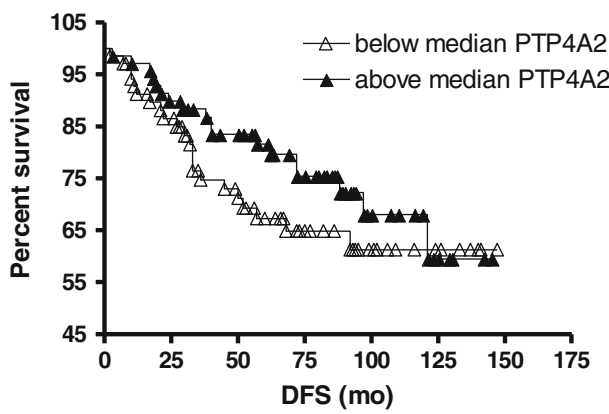

C

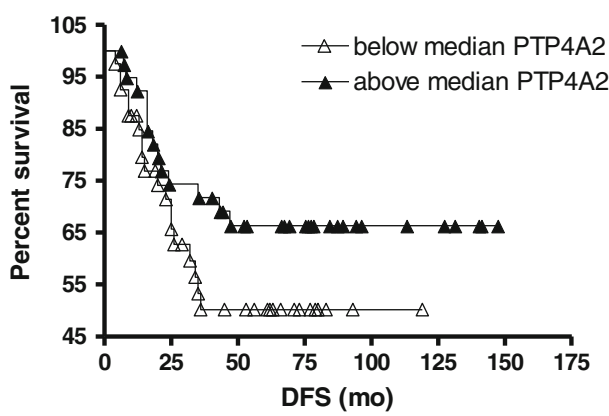

b

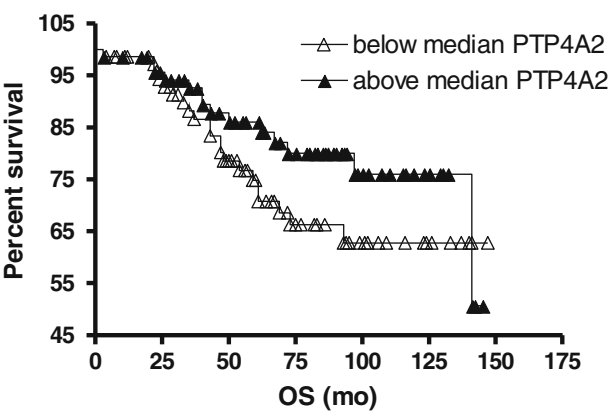

d

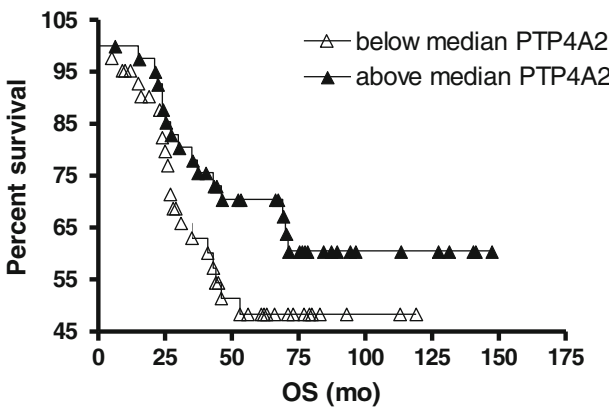


Fig. 10 Relationship of PTP4A2 gene expression with survival in patients with differing PR status of breast cancer. a When patients with $\mathrm{PR}+$ cancers $(n=163)$ were stratified by the median PTP4A2 gene expression level, no significant difference was observed in DFS $(p=0.10)$. b A significant difference was observed in the OS of patients with $\mathrm{PR}+$ cancers $(p=0.01$, $95 \%$ CI of HR $0.25-0.85)$ when stratified by PTP4A2 levels. c When patients with PR- cancers $(n=68)$ were stratified by the median gene expression level, no significant difference was observed in DFS $(p=0.47)$. d No significant difference was observed in OS of patients with $\mathrm{PR}-$ breast cancers $(p=0.50)$ a

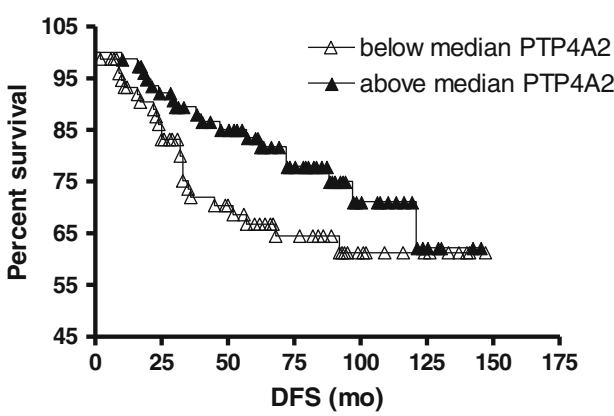

C

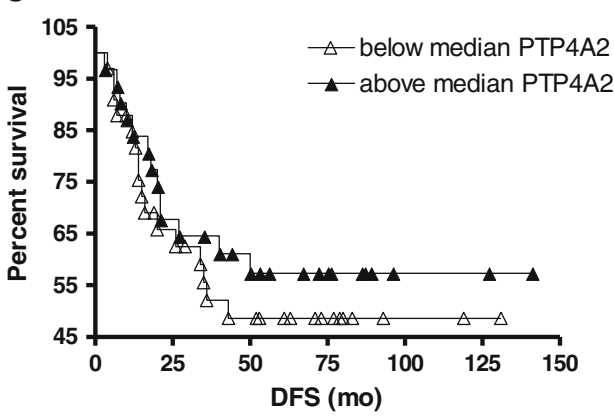

b

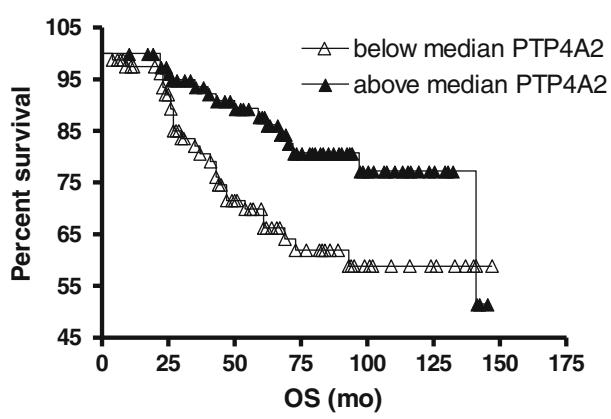

d

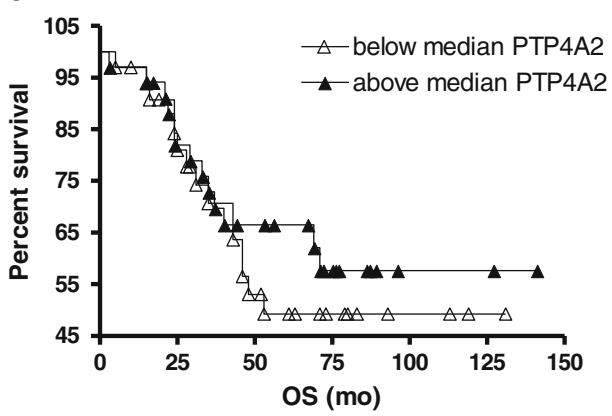

sequences were predicted in the forward strand, and three were predicted in the reverse complement strand. To further investigate the relationship between ER and PTP4A2, we investigated the publicly available data originally published by Carroll et al. [52]. We utilized the 1E-5 Bed files of ER ChIP-on-chip corresponding to an FDR of $\sim 1 \%$ and input the data into the UCSC Genome Browser (using the May 2004 version of the human genome as suggested [52]). No binding sites for ER were identified on PTP4A2. However, no PR data set has been made available to analyze for the presence of PTP4A2 binding. These results encouraged the investigation of a novel relationship between PTP4A2 expression and steroid receptor status of a human breast cancer biopsy.

We tested this possibility using MCF-7 breast cancer cells. After $24 \mathrm{~h}$ serum starvation, cells were treated with $10 \mathrm{nM}$ estradiol-17 $\beta$ for either 6 or $24 \mathrm{~h}$. While qPCR analysis of the cell samples showed that estradiol-17 $\beta$ caused a transient increase in PR gene expression, no such effect was observed for PTP4A2 (Supplementary Fig. 13). In addition, our preliminary experiments using siRNA to silence ER expression also had no effect on PTP4A2 levels (data not shown). Thus, it is unlikely that PTP4A2 expression is regulated directly by ER, at least in these settings.

\section{Discussion}

Recently, the PTP4A2 enzyme was implicated in oncogenesis and in established cancers in a variety of organs, presumably due to its cell signaling activities that play roles in critical cellular processes. PTP4A2 (also known as PRL2) is a PTP that is typically associated with the plasma membrane and early endosome through its c-terminal prenylation [43]. Its function remains unclear; however, several studies suggested its involvement in cell cycle control [43, 48, 53]. Overexpression of PTP4A2 appears to be associated with transformation of mouse fibroblasts and pancreatic epithelial cells and promotion of tumor growth in nude mice [33]. Another member of this family (PTP4A3/PRL-3) was significantly upregulated in metastatic colorectal cancer and neoplastic breast cells; however, no difference was found for PTP4A1/PRL-1 and PTP4A2 expression levels [33, 43]. Strikingly, overexpression of PTP4A2 appears to enhance mammary tumorigenesis in mice [48], and it is suggested to regulate tumor cell migration and invasion in human lung cancer cells through an ERK-dependent signaling pathway [54]. Recently, characterization of knockout mice suggested a role for PTP4A2 in the PTEN/AKT pathway [55]. It will be interesting to test these knockout mice in several breast cancer models. Nevertheless, the expression and role of PTP4A2 in particular warrant further investigation using refined systems to study the enzyme in breast carcinoma.

To address this need, we approached the problem first by taking advantage of the unique, de-identified human breast carcinoma specimens in the IRB-approved biorepository that we established during the past 35 years that is complemented by a comprehensive database containing de-identified information regarding tumor marker status as 
well as features of the tissue specimens (e.g., pathology, grade, nodal status) and patient characteristics and clinical follow-up. Previous studies of 247 human breast cancer tissues collected under standardized, stringent conditions [4] used LCM to procure pure populations of breast carcinoma cells to perform Agilent microarrays to identify gene signatures associated with early disease recurrence $[4,18,56]$. The advantage of this data set is the combined power of global gene expression profiles ( 22,000 genes) and the use of LCMprocured carcinoma cell populations. The utilization of laser capture microdissection allowed nondestructive removal of contaminating cell types that may influence downstream analyses. This extensive data set with the associated clinical follow-up provides a unique resource for identifying specific genes or gene combinations that may alter breast cancer progression and response [16, 56, 57].

Few previous studies suggested that PTP4A2 expression was correlated with tumor formation, migration, and invasion in cell lines and mouse models $[33,48,54]$ and was elevated in primary breast tumors relative to normal breast tissues [48]. However, these studies did not investigate the relationship of PTP4A2 gene expression and the levels of breast cancer biomarkers ER and PR nor the association of the enzyme and biomarkers with breast cancer behavior. Several studies in breast cancer cell lines described genes associated with either ER or PR [58-64], but none of these studies reported results suggesting that PTP4A2 was an ERor PR-regulated gene.

Since these investigations utilized breast cancer tissue biopsies composed of heterogenous cell populations, our study focused on a more definitive approach for examining PTP4A2 expression in human breast tissue biopsies. Homogeneous populations of breast carcinoma cells were isolated by LCM from 247 human breast cancer biopsies collected under standardized, stringent conditions prior to determination of PTP4A2 expression assessed by microarray. PTP4A2 expression was corroborated by qPCR and its relationship to estrogen and progestin receptor levels was determined. Overall and disease-free survival of breast cancer patients was more favorable $(p=0.012$ and $p=0.002$, respectively) when expression of PTP4A2 in breast carcinomas was above the median level compared to biopsies with PTP4A2 levels below median expression. PTP4A2 expression determined either by microarray or qPCR was elevated in either ER-positive or PR-positive breast cancer biopsies compared to ER-negative or PR-negative biopsies suggesting an association between the presence of sex steroid hormone receptors in a breast cancer and the regulation of PTP4A2 gene expression. Furthermore, when the comprehensive clinical follow-up of breast cancer patients was examined with regard to PTP4A2 expression and ER or PR status of the breast cancer biopsy, only overall survival in PR positive breast carcinomas was statistically significant. While these data collectively suggest that PTP4A2 mRNA expression alone may serve as a biomarker for predicting a breast cancer patient's risk of recurrence and overall survival regardless of sex hormone receptor status, PTP4A2 status of a PR+ breast biopsy identifies patients exhibiting different clinical courses. Our results also support the suggestion of Stephens et al. [53] that PRL phosphatases, particularly PTP4A2, are candidate molecular targets for the design and development of new breast cancer therapeutics.

It is not surprising that PTP4A2 may have dual roles in certain carcinomas since the protein product is reported to interact with the beta subunit of Rab geranylgeranyltransferase II functioning as a regulator of its activity. For example, genetic ablation of PTP1B, another member of the PTP family, in mice has been shown to delay mammary tumorigenesis but accelerate lymphomagenesis [65]. Other examples of proteins that may play dual roles in tumorigenesis and metastatic spread include Nrf2 [66] and sirtuins [67]. Thus, it is likely that the cellular context and the stage of carcinoma progression (initiation vs. maintenance) will affect the functional properties of these proteins in relation to cancer. We propose that our findings warrant an expanded investigation of PTP4A2 expression as a biomarker of risk of breast cancer recurrence and survival, in a cooperative clinical trial setting.

\section{Conclusions}

This is the first investigation, to our knowledge, that utilizes LCM to procure homogeneous populations of carcinoma cells to explore the relationship of PTP4A2 expression with estrogen and progestin receptor levels for clinical behavior of human breast cancer. Our studies that were validated by qPCR strongly indicate that overexpression of PTP4A2 mRNA levels in carcinoma biopsies are correlated with disease-free and overall survival of patients independent of ER or PR status. A previous study demonstrated that PTP4A2 levels per se did not differ between normal and malignant breast cancer tissue [33]. However, our study highlights the importance of obtaining homogeneous populations of carcinoma cells for selection of candidate molecules and multivariable analysis in determining the prognostic value of a putative tumor marker. Collectively, our results suggest that PTP4A2 is a powerful biomarker predicting risk of recurrence of breast carcinoma and may be a novel molecular target for the design and development of new therapeutics.

Acknowledgments The authors acknowledge the technical assistance of Amber R. Kelly. This work was funded in part by a Competitive Enhancement Grant to JLW from the Executive Vice President Research and Innovation, University of Louisville and by a grant to SAA and JLW from the Phi Beta Psi Charity Trust. 
Conflict of Interest The authors declare that they have no conflict of interest.

\section{References}

1. Howlader N, Noone AM, Krapcho M, Neyman N, Aminou R, Altekruse SF, Kosary CL, Ruhl J, Tatalovich Z, Cho H, Mariotto A, Eisner MP, Lewis DR, Chen HS, Feuer EJ, Cronin KA (eds) (2012). SEER Cancer Statistics Review, 1975-2009 (Vintage 2009 Populations), National Cancer Institute. Bethesda, MD, http:// seer.cancer.gov/csr/1975_2009_pops09/

2. Emmert-Buck MR, Bonner RF, Smith PD et al (1996) Laser capture microdissection. Science 274:998-1001

3. Simone NL, Bonner RF, Gillespie JW, Emmert-Buck MR, Liotta LA (1998) Laser-capture microdissection: opening the microscopic frontier to molecular analysis. Trends Genet 14:272-276

4. Wittliff JL (2010) Laser capture microdissection and its use in genomics and proteomics. In: Conn PM (ed) Reliable lab solutions: techniques in confocal microscopy. Elsevier, Boston, pp 463-477

5. Boersma BJ, Reimers M, Yi M et al (2008) A stromal gene signature associated with inflammatory breast cancer. Int J Cancer 122:1324-1332

6. Casey T, Bond J, Tighe S et al (2009) Molecular signatures suggest a major role for stromal cells in development of invasive breast cancer. Breast Cancer Res Treat 114:47-62

7. Finak G, Bertos N, Pepin F et al (2008) Stromal gene expression predicts clinical outcome in breast cancer. Nat Med 14:518-527

8. Ma XJ, Dahiya S, Richardson E, Erlander M, Sgroi DC (2009) Gene expression profiling of the tumor microenvironment during breast cancer progression. Breast Cancer Res 11:R7

9. Mellick AS, Day CJ, Weinstein SR, Griffiths LR, Morrison NA (2002) Differential gene expression in breast cancer cell lines and stroma-tumor differences in microdissected breast cancer biopsies revealed by display array analysis. Int J Cancer 100:172-180

10. Santner SJ, Pauley RJ, Tait L, Kaseta J, Santen RJ (1997) Aromatase activity and expression in breast cancer and benign breast tissue stromal cells. J Clin Endocrinol Metab 82:200-208

11. Shekhar MP, Werdell J, Santner SJ, Pauley RJ, Tait L (2001) Breast stroma plays a dominant regulatory role in breast epithelial growth and differentiation: implications for tumor development and progression. Cancer Res 61:1320-1326

12. Burgemeister R (2005) New aspects of laser microdissection in research and routine. J Histochem Cytochem 53:409-412

13. Cole KA, Krizman DB, Emmert-Buck MR (1999) The genetics of cancer-a 3D model. Nat Genet 21:38-41

14. Sluka P, O'Donnell L, McLachlan RI, Stanton PG (2008) Application of laser-capture microdissection to analysis of gene expression in the testis. Prog Histochem Cytochem 42:173-201

15. Bonner RF, Emmert-Buck M, Cole K et al (1997) Laser capture microdissection: molecular analysis of tissue. Science 278:1481-1483

16. Andres SA, Wittliff JL (2011) Relationships of ESR1 and XBP1 expression in human breast carcinoma and stromal cells isolated by laser capture microdissection compared to intact breast cancer tissue. Endocrine 40:212-221

17. Hong SH, Nah HY, Lee JY et al (2004) Analysis of estrogenregulated genes in mouse uterus using cDNA microarray and laser capture microdissection. J Endocrinol 181:157-167

18. Ma XJ, Salunga R, Tuggle JT et al (2003) Gene expression profiles of human breast cancer progression. Proc Natl Acad Sci U S A 100:5974-5979

19. Ma XJ, Wang Z, Ryan PD et al (2004) A two-gene expression ratio predicts clinical outcome in breast cancer patients treated with tamoxifen. Cancer Cell 5:607-616
20. Knight WA III, Osborne CK, Yochmowitz MG, McGuire WL (1980) Steroid hormone receptors in the management of human breast cancer. Ann Clin Res 12:202-207

21. Wittliff JL (1984) Steroid-hormone receptors in breast cancer. Cancer 53:630-643

22. Fisher B, Redmond C, Brown A et al (1981) Treatment of primary breast cancer with chemotherapy and tamoxifen. N Engl J Med 305:1-6

23. Fisher B, Redmond C, Brown A et al (1983) Influence of tumor estrogen and progesterone receptor levels on the response to tamoxifen and chemotherapy in primary breast cancer. J Clin Oncol $1: 227-241$

24. Fleisher M, Dnistrian AM, Sturgeon CM, Wittliff JL (2002) Practice guidelines and recommendations for use of tumor markers in the clinic. In: Diamandis DP et al (eds) Tumor markers: physiology, pathobiology, technology and clinical applications. AACC, Washington, pp 33-63

25. Fekete M, Wittliff JL, Schally AV (1989) Characteristics and distribution of receptors for [D-TRP6]-luteinizing hormonereleasing hormone, somatostatin, epidermal growth factor, and sex steroids in 500 biopsy samples of human breast cancer. J Clin Lab Anal 3:137-147

26. Fitzpatrick SL, Brightwell J, Wittliff JL, Barrows GH, Schultz GS (1984) Epidermal growth factor binding by breast tumor biopsies and relationship to estrogen receptor and progestin receptor levels. Cancer Res 44:3448-3453

27. Clark GM, McGuire WL (1983) Progesterone receptors and human breast cancer. Breast Cancer Res Treat 3:157-163

28. Wittliff JL, Pasic R, Bland KI (1998) Steroid and peptide hormone receptors identified in breast tissue. In: Bland KI, Copeland EM (eds) The breast: comprehensive management of benign and malignant diseases. Saunders, Philadelphia, pp 900-936

29. Cui X, Schiff R, Arpino G, Osborne CK, Lee AV (2005) Biology of progesterone receptor loss in breast cancer and its implications for endocrine therapy. J Clin Oncol 23:7721-7735

30. Julien SG, Dube N, Hardy S, Tremblay ML (2011) Inside the human cancer tyrosine phosphatome. Nat Rev Cancer 11:35-49

31. Freiss G, Vignon F (2004) Protein tyrosine phosphatases and breast cancer. Crit Rev Oncol Hematol 52:9-17

32. Ottenhoff-Kalff AE, van Oirschot BA, Hennipman A et al (1995) Protein tyrosine phosphatase activity as a diagnostic parameter in breast cancer. Breast Cancer Res Treat 33:245-256

33. Radke I, Gotte M, Kersting C et al (2006) Expression and prognostic impact of the protein tyrosine phosphatases PRL-1, PRL-2, and PRL-3 in breast cancer. Br J Cancer 95:347-354

34. Wiener JR, Kerns BJ, Harvey EL et al (1994) Overexpression of the protein tyrosine phosphatase PTP1B in human breast cancer: association with $\mathrm{p} 185 \mathrm{c}$-erbB-2 protein expression. J Natl Cancer Inst 86:372-378

35. Tonks NK, Diltz CD, Fischer EH (1988) Purification of the major protein-tyrosine-phosphatases of human placenta. J Biol Chem 263:6722-6730

36. Lessard L, Stuible M, Tremblay ML (2010) The two faces of PTP1B in cancer. Biochim Biophys Acta 1804:613-619

37. Yip SC, Saha S, Chernoff J (2010) PTP1B: a double agent in metabolism and oncogenesis. Trends Biochem Sci 35:442-449

38. Cheng A, Uetani N, Simoncic PD et al (2002) Attenuation of leptin action and regulation of obesity by protein tyrosine phosphatase 1B. Dev Cell 2:497-503

39. Elchebly M, Payette P, Michaliszyn E et al (1999) Increased insulin sensitivity and obesity resistance in mice lacking the protein tyrosine phosphatase-1B gene. Science 283:1544-1548

40. Klaman LD, Boss O, Peroni OD et al (2000) Increased energy expenditure, decreased adiposity, and tissue-specific insulin sensitivity in protein-tyrosine phosphatase 1B-deficient mice. Mol Cell Biol 20:5479-5489 
41. Zabolotny JM, Bence-Hanulec KK, Stricker-Krongrad A et al (2002) PTP1B regulates leptin signal transduction in vivo. Dev Cell 2:489-495

42. Bentires-Alj M, Neel BG (2007) Protein-tyrosine phosphatase 1B is required for HER2/Neu-induced breast cancer. Cancer Res 67:2420-2424

43. Bessette DC, Qiu D, Pallen CJ (2008) PRL PTPs: mediators and markers of cancer progression. Cancer Metastasis Rev 27:231-252

44. Julien SG, Dube N, Read M et al (2007) Protein tyrosine phosphatase 1B deficiency or inhibition delays ErbB2-induced mammary tumorigenesis and protects from lung metastasis. Nat Genet 39:338-346

45. Bjorge JD, Pang A, Fujita DJ (2000) Identification of proteintyrosine phosphatase $1 \mathrm{~B}$ as the major tyrosine phosphatase activity capable of dephosphorylating and activating c-Src in several human breast cancer cell lines. J Biol Chem 275:41439-41446

46. Cheng A, Bal GS, Kennedy BP, Tremblay ML (2001) Attenuation of adhesion-dependent signaling and cell spreading in transformed fibroblasts lacking protein tyrosine phosphatase-1B. J Biol Chem 276:25848-25855

47. Dube N, Cheng A, Tremblay ML (2004) The role of protein tyrosine phosphatase 1B in Ras signaling. Proc Natl Acad Sci U S A 101:1834-1839

48. Hardy S, Wong NN, Muller WJ, Park M, Tremblay ML (2010) Overexpression of the protein tyrosine phosphatase PRL-2 correlates with breast tumor formation and progression. Cancer Res 70:8959-8967

49. McShane LM, Altman DG, Sauerbrei W et al (2005) Reporting recommendations for tumor marker prognostic studies. J Clin Oncol 23:9067-9072

50. Pasic R, Djulbegovic B, Wittliff JL (1990) Comparison of sex steroid receptor determinations in human breast cancer by enzyme immunoassay and radioligand binding. J Clin Lab Anal 4:430-436

51. Bajic VB, Tan SL, Chong A et al (2003) Dragon ERE Finder version 2: a tool for accurate detection and analysis of estrogen response elements in vertebrate genomes. Nucleic Acids Res 31:3605-3607

52. Carroll JS, Meyer CA, Song J et al (2006) Genome-wide analysis of estrogen receptor binding sites. Nat Genet 38:1289-1297

53. Stephens BJ, Han H, Gokhale V, Von Hoff DD (2005) PRL phosphatases as potential molecular targets in cancer. Mol Cancer Ther 4:1653-1661

54. Wang Y, Lazo JS (2012) Metastasis-associated phosphatase PRL-2 regulates tumor cell migration and invasion. Oncogene 31:818-827

55. Dong Y, Zhang L, Zhang S et al (2012) Phosphatase of regenerating liver 2 (PRL2) is essential for placental development by down-regulating PTEN (phosphatase and tensin homologue deleted on chromosome 10) and activating Akt protein. J Biol Chem 287:32172-32179

56. Wittliff JL, Kruer TL, Andres SA, Smolenkova I (2008) Molecular signatures of estrogen receptor-associated genes in breast cancer predict clinical outcome. Adv Exp Med Biol 617:349-357

57. Kerr DA, Wittliff JL (2011) A five-gene model predicts clinical outcome in $\mathrm{ER}+/ \mathrm{PR}+$, early-stage breast cancers treated with adjuvant tamoxifen. Horm Cancer 2:261-271

58. Clarke R, Shajahan AN, Riggins RB et al (2009) Gene network signaling in hormone responsiveness modifies apoptosis and autophagy in breast cancer cells. J Steroid Biochem Mol Biol 114:8-20

59. Creighton CJ, Cordero KE, Larios JM et al (2006) Genes regulated by estrogen in breast tumor cells in vitro are similarly regulated in vivo in tumor xenografts and human breast tumors. Genome Biol 7:R28

60. Frasor J, Danes JM, Komm B et al (2003) Profiling of estrogen upand down-regulated gene expression in human breast cancer cells: insights into gene networks and pathways underlying estrogenic control of proliferation and cell phenotype. Endocrinology 144:4562-4574

61. Frasor J, Stossi F, Danes JM et al (2004) Selective estrogen receptor modulators: discrimination of agonistic versus antagonistic activities by gene expression profiling in breast cancer cells. Cancer Res 64:1522-1533

62. Harvell DM, Richer JK, Allred DC, Sartorius CA, Horwitz KB (2006) Estradiol regulates different genes in human breast tumor xenografts compared with the identical cells in culture. Endocrinology 147:700-713

63. Knutson TP, Daniel AR, Fan D et al (2012) Phosphorylated and sumoylation-deficient progesterone receptors drive proliferative gene signatures during breast cancer progression. Breast Cancer Res 14:R95

64. Zhu Y, Wang A, Liu MC et al (2006) Estrogen receptor alpha positive breast tumors and breast cancer cell lines share similarities in their transcriptome data structures. Int $\mathrm{J}$ Oncol 29:1581-1589

65. Dube N, Bourdeau A, Heinonen KM et al (2005) Genetic ablation of protein tyrosine phosphatase $1 \mathrm{~B}$ accelerates lymphomagenesis of p53-null mice through the regulation of B-cell development. Cancer Res 65:10088-10095

66. Lau A, Villeneuve NF, Sun Z, Wong PK, Zhang DD (2008) Dual roles of Nrf2 in cancer. Pharmacol Res 58:262-270

67. Bosch-Presegue L, Vaquero A (2011) The dual role of sirtuins in cancer. Genes Cancer 2:648-662 